\title{
PRIMARY CELL LONGEVITY FOR SPINAL CORD STIMULATION: RESULTS FROM THE PRODUCT SURVEILLANCE REGISTRY
}

Jennifer Tinsley, MBA ${ }^{1}$, Shanti Scheffler, PhD², Jeremiah S. Menk ${ }^{3}$, Rachel Slangen, PhD ${ }^{4}$, Eric Buchser, MD5, Sam S. Eldabe, MD ${ }^{6}$; Todd W. Weaver ${ }^{4}$ ${ }^{1}$ Clinical Research, Medtronic IntI Trading Sarl, Tolochenaz, $\mathrm{CH}$; 3 Clinical Biostatistics, Medtronic, Minneapolis, MN, USA

2 Health Economics \& Reimbursement, Medtronic Intl Trading Sarl, Tolochenaz, $\mathrm{CH}$

${ }^{5}$ Department of Anesthesia, Analgesia and Neuromodulation, EHC Hôpital de Morges, Morges, $\mathrm{CH}$

${ }^{6}$ Department of Pain and Anaesthesia, The James Cook Hospital, Middlesbrough, UK

\section{Background and aims}

Spinal Cord Stimulation (SCS) is an effective and well-established treatment for chronic intractable pain of the trunk and/or limbs. SCS is powered by an implantable pulse generator, which can be rechargeable or non-rechargeable primary cell (PC). For PC devices, battery life is an important factor from a clinical and cost perspective. This analysis was conducted to assess the time to battery replacement/longevity in patients who underwent SCS in a real-world registry.

\section{Methods}

The Product Surveillance Registry (PSR, Medtronic) is a prospective, long-term, multicentre global registry to monitor the performance and safety of Medtronic SCS systems. ${ }^{1}$

Battery longevity was analysed using 2,036 PC devices in 1,723 patients across 66 sites on three continents with 3,770 device-years of follow-up (report cut-off date of 30-Apr-2019).

Longevity analyses were completed using a marginal Cox Proportional Hazard regression and Kaplan-Meier methods.

\section{Results}

\section{Median battery survival}

The median survival of PC devices was $\mathbf{5 0 . 6}$ months for all primary cell devices.

Median survival was similar across implant primary indications:

$\begin{array}{lll}49.9 & 50.3 & 56.0 \\ \text { months } & \text { months } & \text { months } \\ \text { in patients } & \text { in patients } & \text { in patients } \\ \text { with Complex } & \text { with Failed } & \text { with other } \\ \text { Regional Pain } & \text { Back Pain } & \text { primary } \\ \text { Syndrome } & (\mathrm{n}=869) & \text { indications } \\ \text { (CRPS) }(\mathrm{n}=229) & & (\mathrm{n}=938)\end{array}$

No statistically significant difference was observed in battery longevity by initial device versus replacement device. Median survival was:

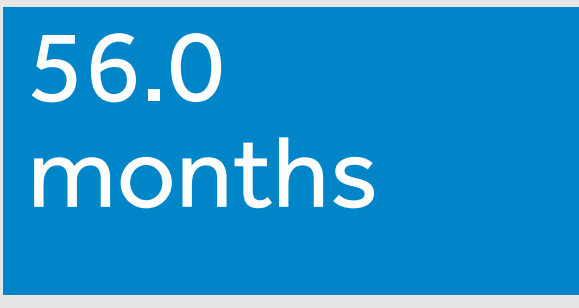

in initial implant devices $(n=475)$

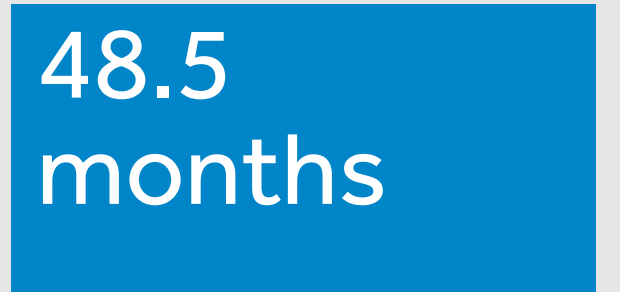

in replacement devices $(n=1,564)$

\section{Results}

\section{Battery longevity survival plot}

for primary cell devices, overall and by primary indication

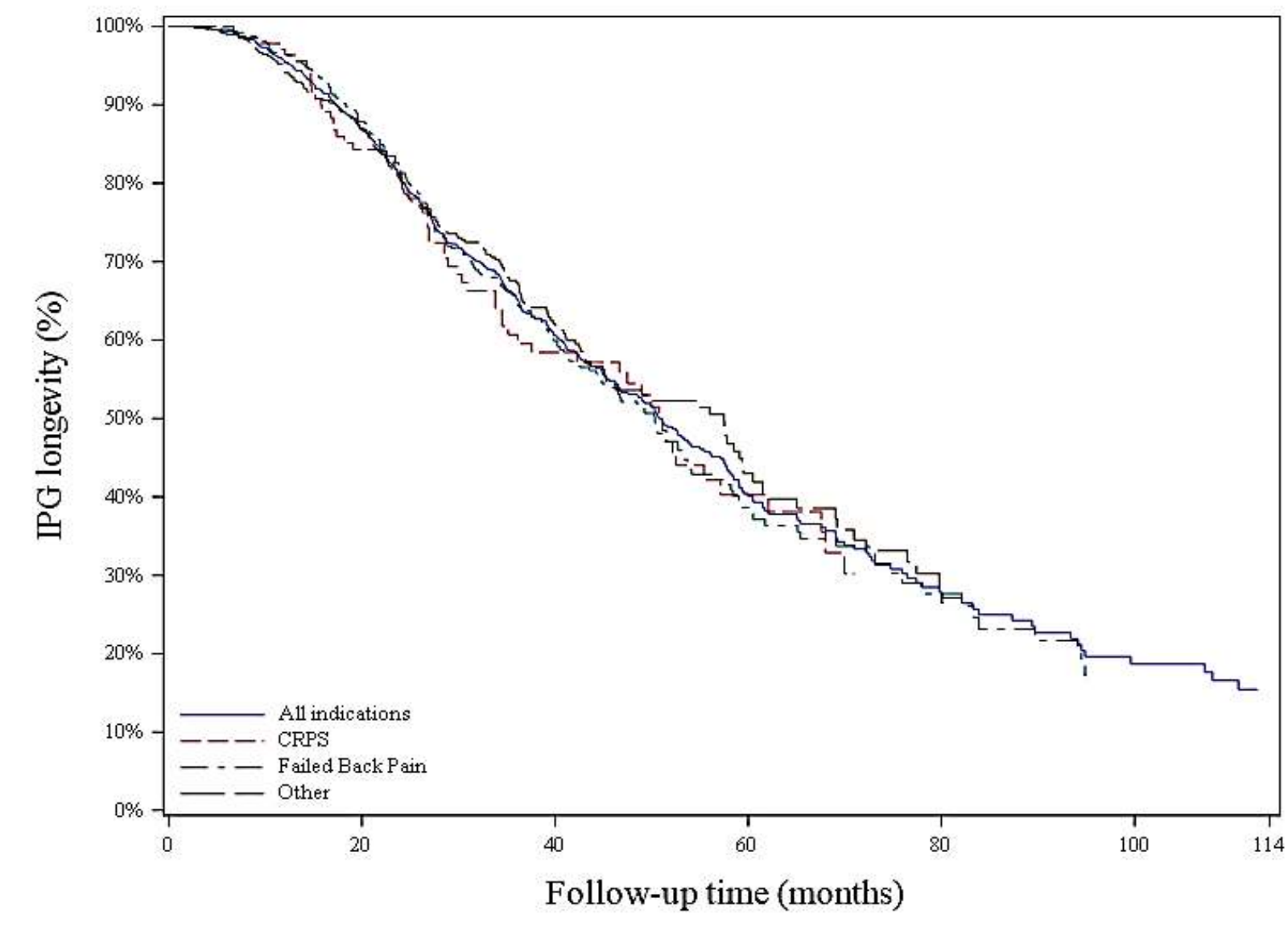

Median battery survival

Battery longevity is impacted by programmed settings, impedance, and patient usage. Mean programmed parameters were summarized for a device along with the standard deviation: mean (SD) $[\mathrm{N}]$.

\begin{tabular}{|l|c|c|c|c|c|c|}
\hline \multirow{4}{*}{ Variables } & \multicolumn{3}{|c|}{ First-time IPG Implant } & \multicolumn{3}{c|}{ Replacement IPG } \\
\cline { 2 - 7 } & FBSS & $\mathbf{C R P S}$ & All & FBSS & CRPS & All \\
\hline Amplitude & 4.7 & $\mathbf{N = 2 0}$ & $\mathbf{N = 3 7 7}$ & $\mathbf{N = 2 2 2}$ & $\mathbf{N = 3 3}$ & $\mathbf{N = 4 5 7}$ \\
& $(3.1)$ & $(2.7)$ & 4.6 & 5.2 & 3.2 & 5.0 \\
& {$[145]$} & {$[20]$} & {$[371]$} & {$[3.1)$} & $(2.3)$ & $(3.4)$ \\
\hline Frequency & 51.4 & 57.7 & 55.7 & 56.9 & 72.4 & 59.3 \\
& $(23.2)$ & $(27.0)$ & $(23.2)$ & $(23.7)$ & $(32.4)$ & $(25.5)$ \\
& {$[145]$} & {$[20]$} & {$[371]$} & {$[219]$} & {$[31]$} & {$[447]$} \\
\hline Impedance & 913.4 & 840.5 & 990.0 & 1128.4 & 596.0 & 1091.9 \\
& $(598.2)$ & $(373.0)$ & $(570.2)$ & $(1044.9)$ & $(282.6)$ & $(1106.0$ \\
& {$[27]$} & {$[5]$} & {$[65]$} & {$[72]$} & {$[8]$} & )$[116]$ \\
\hline Pulse width & 672.8 & 464.3 & 639.5 & 553.0 & 489.4 & 603.6 \\
& $(401.6)$ & $(270.6)$ & $(382.2)$ & $(331.9)$ & $(276.8)$ & $(349.8)$ \\
& {$[145]$} & {$[20]$} & {$[371]$} & {$[219]$} & {$[31]$} & {$[447]$} \\
\hline
\end{tabular}

\section{Discussion \& conclusion}

Overall, the analysis demonstrated the expected performance of battery longevity for PC devices used in SCS therapy from real-world data.

\section{Battery longevity is impacted by programmed settings and patient usage, factors which should be considered when selecting battery type, owing to both the clinical and cost implications from a healthcare payer perspective.}

Acknowledge: Thank you to the PSR Investigators

Schultz DM et al. Spinal Cord Stimulation (SCS) The Implantable Systems Performance Registry (ISPR) Neuromodulation. 2016 Dec;19(8):857-863. 